\title{
Synthesis and Characterization of Novel Aromatic Polyimides from Bis(4-amino-2-biphenyl)ether and Aromatic Tetracarboxylic Dianhydrides
}

\author{
Atsushi MORIKAwa, ${ }^{\dagger}$ Taka-aki FuruKAwA, and Yukari MORIYAMA \\ Department of Materials Science, Faculty of Engineering, Ibaraki University, \\ 4-12-1 Nakanarusawa, Hitachi 316-8511, Japan
}

(Received May 25, 2005; Accepted July 1, 2005; Published October 15, 2005)

\begin{abstract}
A new phenylated diamine, bis(4-amino-2-biphenyl)ether, was synthesized in five steps starting from 3-chloro-4-fluoronitrobenzene. New aromatic polyimides having phenyl groups at the 2- and 2'-positions of the diphenyl ether moiety were prepared from this diamine and various tetracarboxylic dianhydrides by the conventional two-step procedure that included ring-opening polymerization in NMP and subsequent thermal cyclic dehydration. The polyimides were characterized by differential scanning calorimetry (DSC), thermogravimetry, and dynamic mechanical analysis (DMA). Typical polyimides showed excellent thermal stability, and had glass transition temperature $\left(T_{\mathrm{g}}\right)$ above $250^{\circ} \mathrm{C}$. As for the series of polyimides prepared from tetracarboxylic anhydrides having linear phenylene moiety, the introduction of phenyl group at the 2- and $2^{\prime}$-positions of phenyl ether improved thermal and thermo-mechanical properties as well as the solubility of polymers. [DOI 10.1295/polymj.37.759]

KEY WORDS Bis(4-amino-2-biphenyl)ether / Aromatic Polyimide / Differential Scanning Calorimetry / Dynamic Mechanical Analysis / Solubility /
\end{abstract}

Aromatic polyimides are characterized by high glass transition temperature $\left(T_{\mathrm{g}}\right)$ along with high decomposition temperature and good mechanical properties, ${ }^{1}$ and are used in various fields including aerospace and electronic industries. ${ }^{2-7}$ Thereby, the relationships between structures and properties of polyimides have been extensively investigated, and those of polyimides, derived from 4,4'-oxydianiline (ODA) and various dianhydrides, have been most extensively reported. ${ }^{8-19}$ The ODA-based polyimides are known to possess high $T_{\mathrm{g}}$ and excellent mechanical properties in spite of the rotational flexibility at the diphenyl ether units in the polyimides backbone. Such the flexible units are thought to enhance chain mobility and decrease $T_{\mathrm{g}}{ }^{8,9}$ One method to prevent the internal rotation at the diphenyl ether units is expected to be the introduction of bulky substituents into the 2 - and $2^{\prime}$-positions of the diphenyl ether moiety. The rotational flexibility at the diphenyl ether units is expected to be decreased due to the steric effect between the substituents.

We conducted the synthesis of a new diamine monomer, bis(4-amino-2-biphenyl)ether, which had phenyl groups at the 2- and 2'-positions of the diphenyl ether moiety, and aromatic polyimides were derived from it. The properties of polyimides, especially thermal properties, thermal mechanical properties and solubility, were discussed, and compared with the corresponding ODA-based polyimides.

\section{EXPERIMENTAL}

\section{Materials}

Pyromellitic dianhydride(VIIa), 3,3', 4, $4^{\prime}$-biphenyltetracarboxylic dianhydride(VIIb), 3,3',4,4'-benzophenonetetracarboxylic dianhydride(VIIc), 4,4'-oxydiphthalic dianhydride(VIId) and 4,4'-(hexafluoroisopropylidene)-diphthalic anhydride(VIIe) were obtained commercially, and purified by sublimation under reduced pressure. 3,3",4,4" $-p$-Terphenyltetracarboxylic dianhydride(VIIf) was supplied by Hitachi Kasei Kogyo Co., Japan. 3,3"',4,4'"'-p-Quaterphenyltetracarboxylic(VIIg) dianhydride, $3,3^{\prime \prime \prime \prime}, 4,4^{\prime \prime \prime \prime}-p$ quinquephenyltetracarboxylic dianhydride(VIIh) and $3,3^{\prime \prime \prime \prime \prime}, 4,4^{\prime \prime \prime \prime \prime}$ - $p$-sexiphenyltetracarboxylic dianhydride (VIIi) were synthesized according to the method reported previously. ${ }^{16-18} \quad N$-Methyl-2-pyrrolidone (NMP), $N, N$-dimethylacetamide (DMAc) and $N, N$ dimethylformamide (DMF) were purified by vacuum distillation over calcium hydride. Ethanol was purified by distillation. 3-Chloro-4-fluoronitrobenzene (I) and phenylboronic acid were obtained from Tokyo Kasei Kogyo Co., Japan and used without purification. Tetrakis(triphenylphosphine)palladium $\quad\left(\mathrm{Pd}\left(\mathrm{PPh}_{3}\right)_{4}\right)$ and sodium hydroxide were obtained from Kanto Kagaku Co., Japan.

\section{Monomer Synthesis \\ 4-Fluoro-3-phenylnitrobenzene (II). To a flask}

${ }^{\dagger}$ To whom correspondence should be addressed (E-mail: morikawa@mx.ibaraki.ac.jp). 
equipped with a reflux condenser, $17.55 \mathrm{~g}(100 \mathrm{mmol})$ of $\mathbf{I}, 12.19 \mathrm{~g}$ ( $100 \mathrm{mmol})$ of phenylboronic acid, 13.82 $\mathrm{g}(100 \mathrm{mmol})$ of potassium carbonate and $120 \mathrm{~mL}$ deoxygenated DMF were added. The flask was flushed with nitrogen, and $0.5 \mathrm{~g}$ of tetrakis(triphenylphosphine)palladium $\left(\mathrm{Pd}\left(\mathrm{PPh}_{3}\right)_{4}\right)$ were added to the reaction mixture. After the mixture was stirred at $90^{\circ} \mathrm{C}$ for $8 \mathrm{~h}$, precipitated salts were removed by filtration, and the solvent was removed by distillation under reduced pressure. The residue was distilled under reduced pressure to give pure II. Yield: $12.92 \mathrm{~g}(60 \%)$. Bp: $128-135^{\circ} \mathrm{C}$ ( 1 torr). Mp: $47-48^{\circ} \mathrm{C}$. IR spectrum (KBr) exhibited absorption bands at $1525 \mathrm{~cm}^{-1}, 1348$ $\mathrm{cm}^{-1}\left(\mathrm{NO}_{2}\right)$ and $1100 \mathrm{~cm}^{-1}$ (Ar-F).

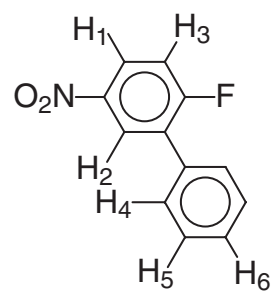

${ }^{1} \mathrm{H}$ Nuclear magnetic resonance (NMR) spectrum [ $\delta$ in $\mathrm{CDCl}_{3}$ ] showed signals at $7.30\left(\mathrm{dd}, 1 \mathrm{H}, J_{\mathrm{HH}}=\right.$ $\left.9.2 \mathrm{~Hz}, J_{H F}=9.2 \mathrm{~Hz}, \mathrm{H} 3\right), 7.41-7.53(\mathrm{~m}, 3 \mathrm{H}, \mathrm{H} 5$ and $\mathrm{H} 6), 7.53-7.59(\mathrm{~m}, 2 \mathrm{H}, \mathrm{H} 4), 8.18-8.24(\mathrm{~m}, 1 \mathrm{H}$, $\mathrm{H} 1)$ and $8.38\left(\mathrm{dd}, 1 \mathrm{H}, J_{H H}=2.9 \mathrm{~Hz}, J_{H F}=6.6 \mathrm{~Hz}\right.$, $\mathrm{H} 2)$ ppm. ${ }^{13} \mathrm{C}$ NMR spectrum $\left[\delta\right.$ in $\left.\mathrm{CDCl}_{3}\right]$ showed signals at $117.02(\mathrm{~d}, J=25.5 \mathrm{~Hz}), 124.38(\mathrm{~d}, J=9.6$ $\mathrm{Hz}), 126.41(\mathrm{~d}, J=6.4 \mathrm{~Hz}), 128.66,128.74,128.75$, $130.28(\mathrm{~d}, J=15.9 \mathrm{~Hz}), 133.16,144.26(\mathrm{~d}, J=3.2$ $\mathrm{Hz})$ and $162.96(\mathrm{~d}, J=259.8 \mathrm{~Hz}) \mathrm{ppm}$.

Anal. Calcd for $\mathrm{C}_{12} \mathrm{H}_{8} \mathrm{NO}_{2} \mathrm{~F}$ : C, 66.36\%; $\mathrm{H}, 3.71 \%$; N, 6.45\%. Found: C, 66.08\%; H, 3.50\%; N, 6.32\%.

4-Ethoxy-3-phenylnitrobenzene (III). To a solution of $7.50 \mathrm{~g}(34.5 \mathrm{mmol})$ of $\mathbf{I I}$ in $80 \mathrm{~mL}$ of ethanol was added dropwise $1.38 \mathrm{~g}(34.5 \mathrm{mmol})$ of sodium hydroxide in $5.0 \mathrm{~mL}$ of distilled water at room temperature, and the mixture was refluxed for $12 \mathrm{~h}$. After the mixture was cooled to room temperature, the crude III was precipitated. The pure III was obtained by recrystallization from ethanol. Yield: $7.95 \mathrm{~g}$ (95\%). Mp: $110-111^{\circ} \mathrm{C}$. IR spectrum (KBr) exhibited absorption bands at $2985 \mathrm{~cm}^{-1}, 2930 \mathrm{~cm}^{-1},(\mathrm{C}-\mathrm{H}), 1510 \mathrm{~cm}^{-1}$, $1337 \mathrm{~cm}^{-1}\left(\mathrm{NO}_{2}\right)$ and $1106 \mathrm{~cm}^{-1}\left(\mathrm{Ar}-\mathrm{O}-\mathrm{C}_{2} \mathrm{H}_{5}\right)$.

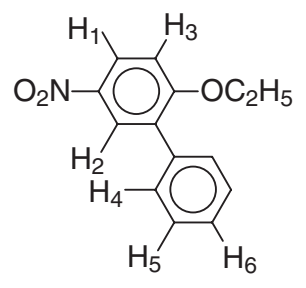

${ }^{1} \mathrm{H}$ NMR spectrum $\left[\delta\right.$ in $\mathrm{CDCl}_{3}$ ] showed signals at $1.41\left(\mathrm{t}, 3 \mathrm{H}, J=7.0 \mathrm{~Hz},-\mathrm{CH}_{3}\right), 4.17$ (q, $2 \mathrm{H}, J=7.0$ $\left.\mathrm{Hz},-\mathrm{CH}_{2}-\right), 7.00(\mathrm{~d}, 1 \mathrm{H}, J=8.8 \mathrm{~Hz}, \mathrm{H} 3), 7.34-$ $7.47(\mathrm{~m}, 3 \mathrm{H}, \mathrm{H} 5$ and $\mathrm{H} 6), 7.52-7.56(\mathrm{~m}, 2 \mathrm{H}, \mathrm{H} 4)$, $8.20(\mathrm{dd}, 1 \mathrm{H}, J=8.8 \mathrm{~Hz}, J=2.9 \mathrm{~Hz}, \mathrm{H} 1)$ and 8.24 (d, $J=2.9 \mathrm{~Hz}, \mathrm{H} 2)$ ppm. ${ }^{13} \mathrm{C}$ NMR spectrum $[\delta$ in $\mathrm{CDCl}_{3}$ ] showed signals at $14.39,64.71,111.29$, $124.54,126.28,127.69,128.01,129.23,131.10$, $136.08,141.10$ and $160.67 \mathrm{ppm}$.

Anal. Calcd for $\mathrm{C}_{14} \mathrm{H}_{13} \mathrm{NO}_{3}$ : C, 69.12\%; H, 5.39\%; N, 5.76\%. Found: C, $68.88 \%$; H, 5.20\%; N, 5.64\%.

4-Hydroxy-3-phenylnitrobenzene (IV). $\quad 7.95 \mathrm{~g}$ $(32.7 \mathrm{mmol})$ of III was heated together with $50.0 \mathrm{~g}$ of pyridine hydrochloride at reflux temperature for $30 \mathrm{~min}$. After the reaction mixture became homogeneous, it was poured into water $(450 \mathrm{~mL})$. The mixture was extracted three times with $100 \mathrm{~mL}$ of dichloromethane. The combined extract was dried over anhydrous magnesium sulfate. After evaporation of the solvent, the residue was distilled under reduced pressure (glass tube oven) to afford pure 4-hydroxy-3-phenylnitrobenzene (IV). Yield: $5.22 \mathrm{~g}(74 \%)$. Bp: $210^{\circ} \mathrm{C}$ (1 torr). Mp: $125-126^{\circ} \mathrm{C}$. IR spectrum (KBr) exhibited absorption bands at $3550-3100 \mathrm{~cm}^{-1}, 1496 \mathrm{~cm}^{-1}$ and $1327 \mathrm{~cm}^{-1}\left(\mathrm{NO}_{2}\right)$.

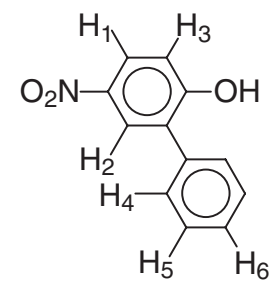

${ }^{1} \mathrm{H}$ NMR spectrum $\left[\delta\right.$ in $\left.\mathrm{CDCl}_{3}\right]$ showed signals at $5.98($ broad s, $1 \mathrm{H},-\mathrm{OH}), 7.07(\mathrm{~d}, 1 \mathrm{H}, J=8.8 \mathrm{~Hz}$, H3), 7.44-7.51 (m, 3H, H5 and H6), 7.55 (m, 2H, H4), $8.21(\mathrm{dd}, 1 \mathrm{H}, J=8.8 \mathrm{~Hz}, J=2.6 \mathrm{~Hz}, \mathrm{H} 1)$ and 8.24 (d, $J=2.6 \mathrm{~Hz}, \mathrm{H} 2)$ ppm. ${ }^{13} \mathrm{C}$ NMR spectrum $[\delta$ in $\mathrm{CDCl}_{3}$ ] showed signals at $116.15,125.05,126.06$, $128.44,128.72,128.95,129.61,134.3,141.45$ and $157.84 \mathrm{ppm}$.

Anal. Calcd for $\mathrm{C}_{12} \mathrm{H}_{9} \mathrm{NO}_{3}: \mathrm{C}, 66.98 \% ; \mathrm{H}, 4.22 \%$; N, 6.51\%. Found: C, 66.79\%; H, 4.11\%; N, 6.27\%.

Bis(4-nitro-2-biphenyl)ether $(\boldsymbol{V})$. In a flask, a mixture of $5.26 \mathrm{~g}(24.2 \mathrm{mmol})$ of II, $5.22 \mathrm{~g}(24.2 \mathrm{mmol})$ of IV, $3.35 \mathrm{~g}(24.2 \mathrm{mmol})$ of potassium carbonate, $30 \mathrm{~mL}$ of toluene and $80 \mathrm{~mL}$ of DMAc was stirred at $130^{\circ} \mathrm{C}$ for $1 \mathrm{~h}$. The water formed during the reaction was removed by azeotropic distillation using toluene. Next, the reaction temperature was raised to $160{ }^{\circ} \mathrm{C}$, and the mixture was stirred at this temperature for $3 \mathrm{~h}$. The reaction mixture was cooled at $80^{\circ} \mathrm{C}$, and the solvent was evaporated under a reduce pressure of 1525 torr. The residue was washed with $250 \mathrm{~mL}$ of water and extracted twice with $200 \mathrm{~mL}$ of dichloromethane. The combined extract was dried over anhydrous magnesium sulfate, and the solvent was evaporated. After the residue was purified by silica gel chromatography eluted by a mixture of dichloromethane and hexane 
(6:4), pure $\mathbf{V}$ was obtained by recrystallization from acetic acid. Yield: $4.28 \mathrm{~g}(43 \%)$. Mp: $143-144{ }^{\circ} \mathrm{C}$. IR spectrum $(\mathrm{KBr})$ exhibited absorption bands at 1520 $\mathrm{cm}^{-1}, 1344 \mathrm{~cm}^{-1}\left(\mathrm{NO}_{2}\right)$ and $1224 \mathrm{~cm}^{-1}$ (Ar-O-Ar).

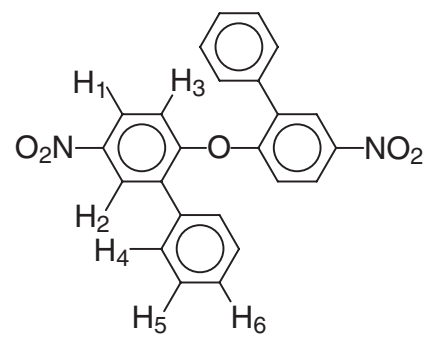

${ }^{1} \mathrm{H}$ NMR spectrum $\left[\delta\right.$ in $\mathrm{CDCl}_{3}$ ] showed signals at 7.02 (d, 2H, $J=8.8 \mathrm{~Hz}, \mathrm{H} 3), 7.33-7.42$ (m, 10H, H4, $\mathrm{H} 5$ and H6), $8.15(\mathrm{dd}, 2 \mathrm{H}, J=8.8 \mathrm{~Hz}, J=2.9 \mathrm{~Hz}$, $\mathrm{H} 1)$ and $8.30(\mathrm{~d}, 2 \mathrm{H}, J=2.9 \mathrm{~Hz}, \mathrm{H} 2) \mathrm{ppm} .{ }^{13} \mathrm{C} \mathrm{NMR}$ spectrum $\left[\delta\right.$ in $\mathrm{CDCl}_{3}$ ] showed signals at 118.82 , $124.21,127.03,128.44,128.54,129.00,134.24$, 134.83, 144.07 and $157.31 \mathrm{ppm}$.

Anal. Calcd for $\mathrm{C}_{24} \mathrm{H}_{16} \mathrm{~N}_{2} \mathrm{O}_{5}$ : C, 69.90\%; H, 3.91\%; N, 6.79\%. Found: C, 69.71\%; H, 3.85\%; N, 6.68\%.

Synthesis of $\boldsymbol{V}$ from $\boldsymbol{I I}$. In a flask, a mixture of $8.69 \mathrm{~g}(40.0 \mathrm{mmol})$ of II, $5.53 \mathrm{~g}(40.0 \mathrm{mmol})$ of potassium carbonate and $50 \mathrm{~mL}$ of DMF was stirred at $140{ }^{\circ} \mathrm{C}$ for $72 \mathrm{~h}$. The reaction mixture was cooled at $80^{\circ} \mathrm{C}$, and the solvent was evaporated under a reduce pressure of 15-25 torr. The residue was washed with $250 \mathrm{~mL}$ of water and extracted twice with $200 \mathrm{~mL}$ of dichloromethane. The combined extract was dried over anhydrous magnesium sulfate, and the solvent was evaporated. After the residue was purified by silica gel chromatography eluted by a mixture of dichloromethane and hexane (6:4), pure $\mathbf{V}$ was obtained by recrystallization from acetic acid. Yield: $5.63 \mathrm{~g}$ (68\%). Mp: $143-144^{\circ} \mathrm{C}$. IR spectrum (KBr) exhibited absorption bands at $1520 \mathrm{~cm}^{-1}, 1345 \mathrm{~cm}^{-1}\left(\mathrm{NO}_{2}\right)$ and $1226 \mathrm{~cm}^{-1}$ (Ar-O-Ar).

${ }^{1} \mathrm{H}$ NMR spectrum $\left[\delta\right.$ in $\mathrm{CDCl}_{3}$ ] showed signals at $7.02(\mathrm{~d}, 2 \mathrm{H}, J=8.8 \mathrm{~Hz}, \mathrm{H} 3), 7.33-7.42(\mathrm{~m}, 10 \mathrm{H}, \mathrm{H} 4$, $\mathrm{H} 5$ and H6), $8.14(\mathrm{dd}, 2 \mathrm{H}, J=8.8 \mathrm{~Hz}, J=2.9 \mathrm{~Hz}$, $\mathrm{H} 1)$ and $8.30(\mathrm{~d}, 2 \mathrm{H}, J=2.9 \mathrm{~Hz}, \mathrm{H} 2) \mathrm{ppm} .{ }^{13} \mathrm{C} \mathrm{NMR}$ spectrum $\left[\delta\right.$ in $\mathrm{CDCl}_{3}$ ] showed signals at 118.83 , $124.21,127.03,128.44,128.56,129.00,134.24$, $134.83,144.08$ and $157.31 \mathrm{ppm}$.

Anal. Calcd for $\mathrm{C}_{24} \mathrm{H}_{16} \mathrm{~N}_{2} \mathrm{O}_{5}$ : C, 69.82\%; H, 3.94\%; N, 6.75\%. Found: C, 69.71\%; H, 3.85\%; N, 6.68\%.

Bis(4-amino-2-biphenyl)ether (VI). A mixture of $4.28 \mathrm{~g}(10.4 \mathrm{mmol})$ of $\mathbf{V}$ and $0.3 \mathrm{~g}$ of $10 \% \mathrm{Pd} / \mathrm{C}$ in $\mathrm{mL} \mathrm{DMF}$ at $60^{\circ} \mathrm{C}$ for $12 \mathrm{~h}$ under a hydrogen atmosphere. After the $\mathrm{Pd} / \mathrm{C}$ was removed by filtration, the solvent was evaporated under reduced pressure. The residue was recrystallized from toluene to give a pure VI. Yield: $3.08 \mathrm{~g}$ (84\%). Mp: $204-205^{\circ} \mathrm{C}$. IR spectrum $(\mathrm{KBr})$ exhibited absorption bands at 3375 $\mathrm{cm}^{-1}, 3354 \mathrm{~cm}^{-1}\left(\mathrm{NH}_{2}\right)$ and $1213 \mathrm{~cm}^{-1}$ (Ar-O-Ar).

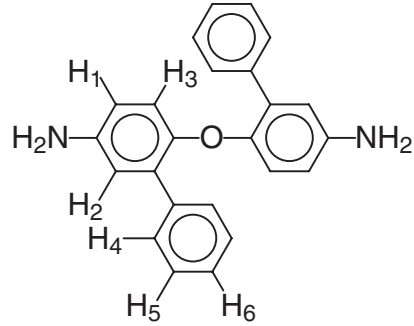

${ }^{1} \mathrm{H}$ NMR spectrum $\left[\delta\right.$ in $\mathrm{CDCl}_{3}$ ] showed signals at 2.50-3.70 (broad s, 4H, $-\mathrm{NH}_{2}$ ), 6.57 (dd, $2 \mathrm{H}, J=8.4$ $\mathrm{Hz}, J=2.9 \mathrm{~Hz}, \mathrm{H} 1), 6.69(\mathrm{~d}, 2 \mathrm{H}, J=8.4 \mathrm{~Hz}, \mathrm{H} 3)$, $6.70(\mathrm{~d}, 2 \mathrm{H}, \mathrm{J}=2.9 \mathrm{~Hz}, \mathrm{H} 2), 7.21-7.33$ (m, 6H, H5 and H6) and 7.34-7.42 (m, 4H, H4) ppm. ${ }^{13} \mathrm{C}$ NMR spectrum $\left[\delta\right.$ in $\left.\mathrm{CDCl}_{3}\right]$ showed signals at 115.35 , $117.74,119.57,126.87,127.76,129.16,133.50$, 138.03, 141.01 and $147.42 \mathrm{ppm}$.

Anal. Calcd for $\mathrm{C}_{24} \mathrm{H}_{20} \mathrm{~N}_{2} \mathrm{O}$ : C, 81.79\%; H, 5.72\%; N, 7.95\%. Found: C, 81.51\%; H, 5.50\%; N, 7.81\%.

\section{Polymerization}

Polyimide IXa from VI and VIIa. In a three necked flask, $0.433 \mathrm{~g}(1.99 \mathrm{mmol})$ of VIIa was added to a solution of $0.700 \mathrm{~g}(1.99 \mathrm{mmol})$ of VI in $8.0 \mathrm{~mL}$ of NMP in one portion. The mixture was stirred at room temperature for $6 \mathrm{~h}$ under nitrogen. A part of the resulting viscous solution poured into $200 \mathrm{~mL}$ of methanol. The precipitated polymer was filtrated, washed with methanol and dried under vacuum. The inherent viscosity of polyamic acid VIIIa was $0.87 \mathrm{dlg}^{-1}$ in NMP at $30^{\circ} \mathrm{C}$. The NMP solution was cast onto a glass plate and the solvent was removed at $80^{\circ} \mathrm{C}$. The thermal cyclodehydration of the polyamic acid was performed by successive heating at $100{ }^{\circ} \mathrm{C}$ for $1 \mathrm{~h}, 200^{\circ} \mathrm{C}$ for $1 \mathrm{~h}$, and finally $300^{\circ} \mathrm{C}$ for $1 \mathrm{~h}$ under vacuum. The IR spectrum (film) exhibited absorption band at $1780 \mathrm{~cm}^{-1}$ and $1720 \mathrm{~cm}^{-1}(\mathrm{C}=\mathrm{O})$ and 1360 $\mathrm{cm}^{-1}(\mathrm{C}-\mathrm{N})$. IR spectrum (film) exhibited absorption bands at $1780 \mathrm{~cm}^{-1}, 1720 \mathrm{~cm}^{-1}(\mathrm{C}=\mathrm{O})$ and 1360 $\mathrm{cm}^{-1}(\mathrm{C}-\mathrm{N})$.

Anal. Calcd for $\mathrm{C}_{34} \mathrm{H}_{18} \mathrm{~N}_{2} \mathrm{O}_{5}$ : C, 76.40\%; H, 3.39\%; N, 5.24\%. Found: C, 75.92\%; H, 3.35\%; N, 5.01\%.

\section{Measurement}

${ }^{1} \mathrm{H}$ and ${ }^{13} \mathrm{C}$ NMR spectra were recorded on a JNMGSX400 FT-NMR spectrometer and SHIMADZU spectro Photometer IR 435, respectively. X-Ray diffraction was performed with a Rigaku RAD-B system. For differential scanning calorimetry (DSC) and thermogravimetry (TG) a Shimadzu DSC-60 and Rigaku thermal analysis station TG 8110 were used, respectively, and measurement was made at a heating rate of $10^{\circ} \mathrm{C} \mathrm{min}^{-1}$ in air or nitrogen. Dynamic mechanical analysis (DMA) was performed with the Advanced Rheometric Expansion System at $1.0 \mathrm{~Hz}$ at $5{ }^{\circ} \mathrm{C} \mathrm{min}^{-1}$. 


\section{RESULTS AND DISCUSSION}

\section{Monomer Synthesis}

New phenylated diamine having phenyl groups at the 2- and 2'-positions of the diphenyl ether moiety, bis(4-amino-2-biphenyl)ether, was synthesized in five steps starting from 3-chloro-4-fluoronitrobenzene I according to eq 1 . Cross-coupling ${ }^{20}$ of $\mathbf{I}$ with phenylboronic acid yielded 4-fluoro-3-phenyl nitrobenzene II. Subsequent reaction of II with ethanol in the presence of sodium hydroxide afforded 4-ethoxy-3-phenylnitrobenzene III, and III was treated with pyridine hydrochloride to give 4-hydroxy-3-phenylnitrobenzene IV. The reaction between IV and II gave bis(4-nitro-2-biphenyl)ether $\mathbf{V}$, and bis(4-amino-2biphenyl)ether VI was obtained by hydrogenation of V using $\mathrm{Pd} / \mathrm{C}$ as a catalyst.
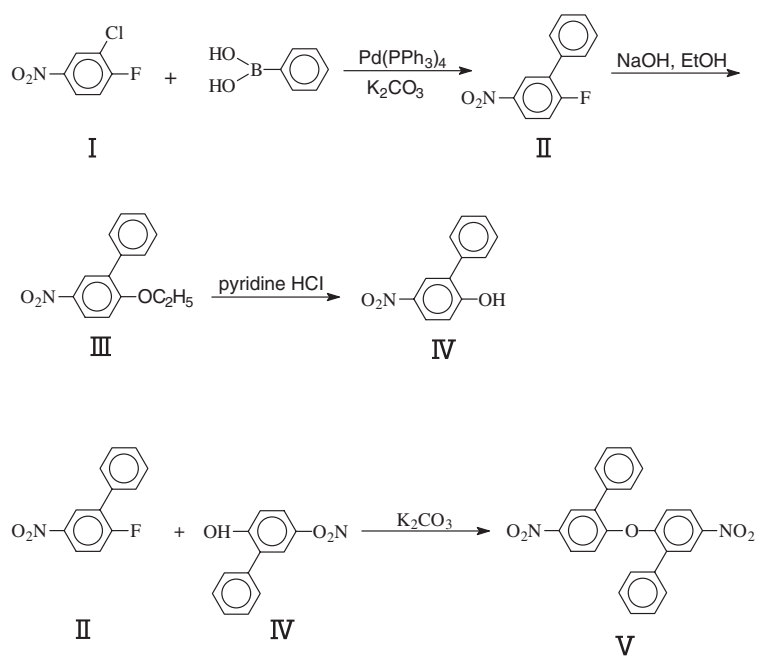

(1)

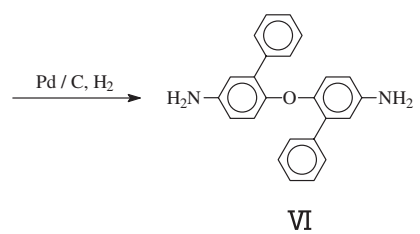

Later, it was found that the compound $\mathbf{V}$ could be synthesized in one step by treating II with potassium carbonate in DMF at $140{ }^{\circ} \mathrm{C}$ (see experimental section).

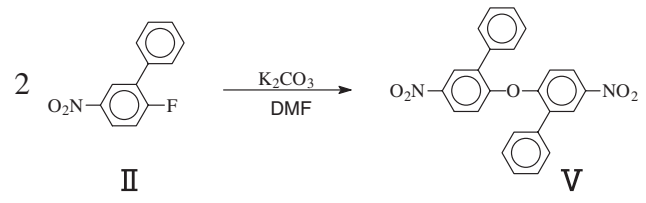

Chemical structures were confirmed by IR, NMR spectra and elemental analysis. In the synthesis of compound $\mathbf{V}$, the spin-spin coupling of the protons (H1 and H3) with fluorine atom, which was observed on the ${ }^{1} \mathrm{H}$ NMR spectrum of II, disappeared, and the characteristic ether band at $1224 \mathrm{~cm}^{-1}$ appeared on the IR spectrum. Compound VI showed IR character- istic absorption bond at 3375 and $3354 \mathrm{~cm}^{-1}$ of amino group. The ${ }^{13} \mathrm{C}$ NMR spectrum of exhibited 10 peaks due to symmetry, indicating the formation of the postulated diamine (VI). Elemental analysis of all the compounds was also in good agreement with calculated results for the proposed structures.

2D-COSY NMR spectra of IV and $\mathbf{V}$ were shown in Figure 1. In the both 2D-COSY NMR spectra, the correlations between the proton of $\mathrm{H} 3$ and the protons of $\mathrm{H} 1$ and $\mathrm{H} 2$ as well as the correlations between the proton of $\mathrm{H} 3$ and the phenyl protons ( $\mathrm{H} 4, \mathrm{H} 5$, and $\mathrm{H} 6)$ were observed. However, correlation between the phenyl protons at 2-position and those at 2'-position, which suggested the influence of the phenyl groups on the flexibility of the diphenyl ether, was not observed in the spectrum of $\mathbf{V}$. The signals from the phenyl protons of $\mathbf{V}$ appeared in the field higher than those of IV. The higher magnetic field shift might be due to the interaction between the phenyl groups at $2-$, and $2^{\prime}$-position.

\section{Polymer Synthesis}

Aromatic polyimides (IXa-h) were synthesized by the usual two-step procedure involving the ring-opening polymerization of the diamine (VI) to tetracarboxylic dianhydrides (VIIa-h) and subsequent thermal cyclodehydration as shown in eq 3 .
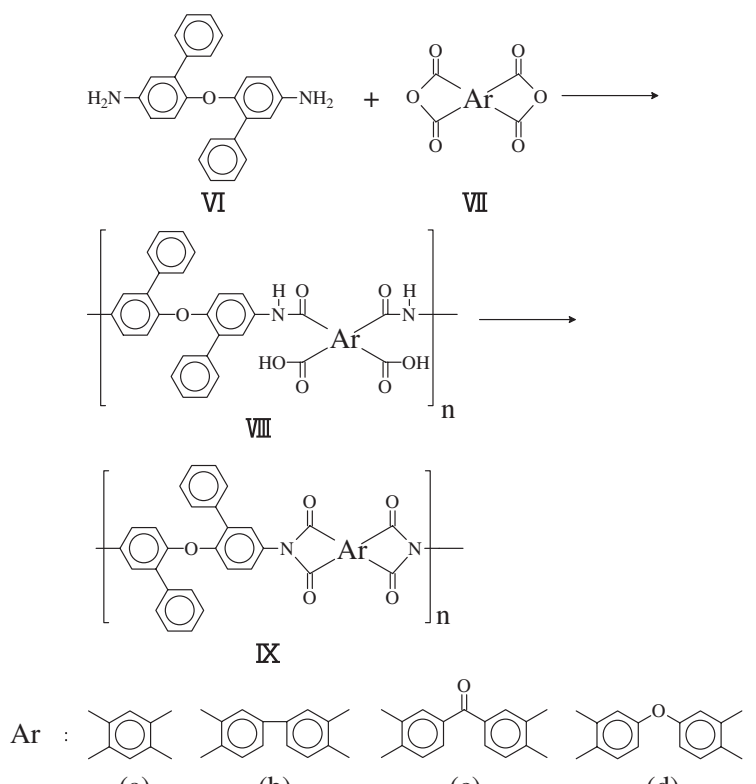

(a)

(b)

(c)

(d)

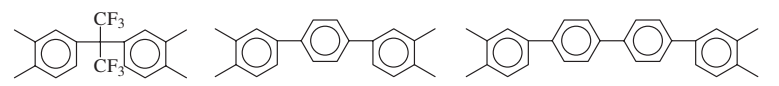

(e)

(f)

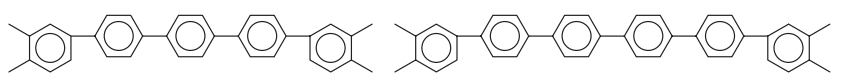

(h)
In the first step, ring-opening polymerizations were carried out in NMP at room temperature, leading to the formation of polyamic acids having inherent 


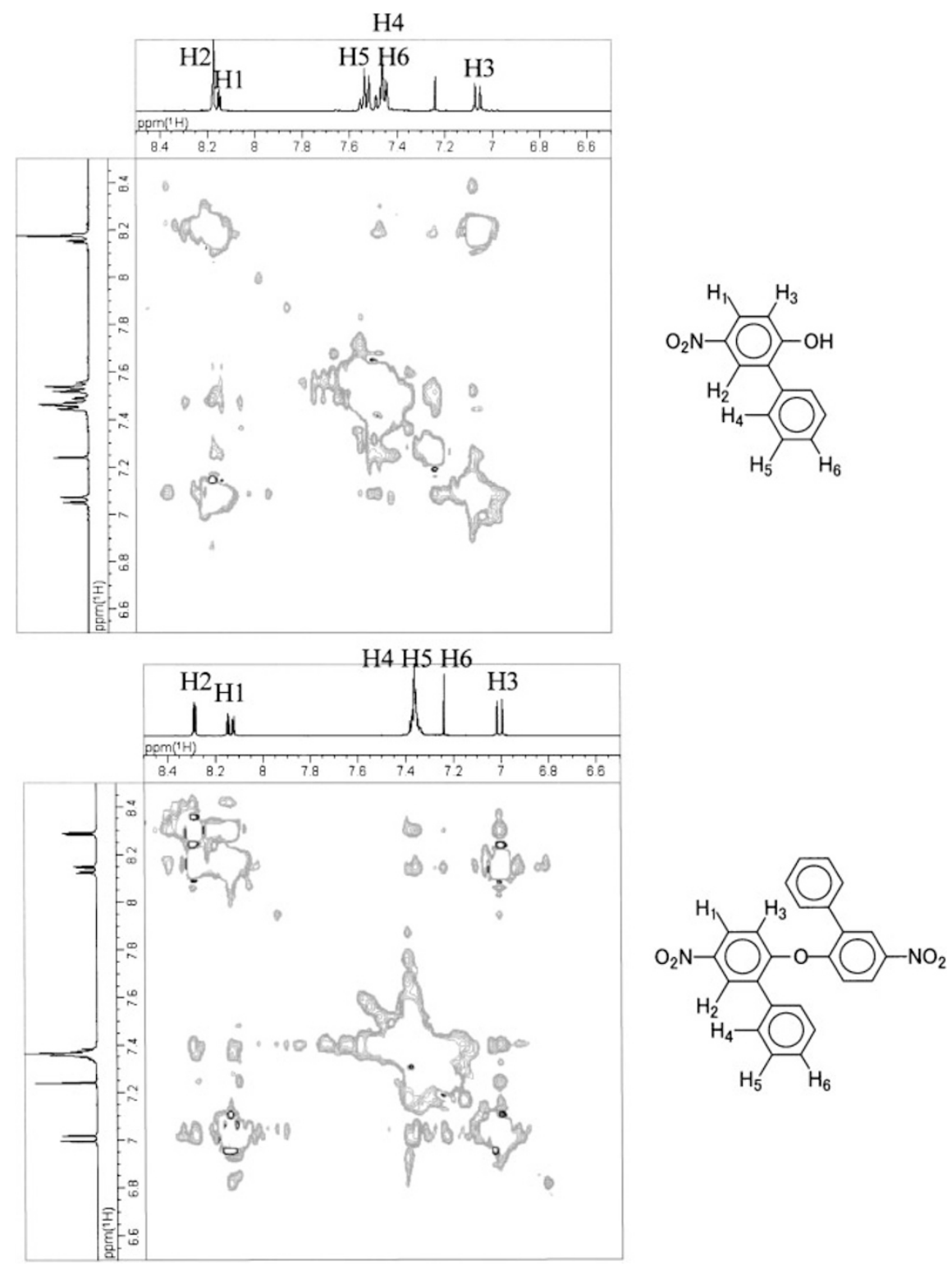

Figure 1. 2D COSY NMR spectra of IV and V.

viscosities of $0.38-0.92 \mathrm{dlg}^{-1}$ in NMP (Table I). The polymerization proceeded in homogeneous solution in reaction media (NMP), and viscosity of polyamic acid were rather high.

In the second step, the thermal conversion of the polyamic acids to polyimides was performed by heating precursor polymers in the form of film successively at $100^{\circ} \mathrm{C}$ for $1 \mathrm{~h}, 200^{\circ} \mathrm{C}$ for $1 \mathrm{~h}$, and finally $300^{\circ} \mathrm{C}$ for $1 \mathrm{~h}$ under vacuum. These polyimides gave tough films except IXe. Polyimide IXe was gave only brittle films.

The formation of polyimides were confirmed by appearance of absorption bands at around $1780 \mathrm{~cm}^{-1}$ and $1720 \mathrm{~cm}^{-1}(\mathrm{C}=\mathrm{O})$ and about $1360 \mathrm{~cm}^{-1}(\mathrm{C}-\mathrm{N})$ characteristic of imide group in the IR spectra. Elemental analysis values were in close agreement with those calculated values, thus also supporting polyimide formation.
Table I. Synthesis of polyamic acid

\begin{tabular}{cccc}
\hline Dianhydride & Polyamic acid & Yield $\%$ & $\eta_{\text {inh }}{ }^{\mathrm{c}} / \mathrm{dlg}^{-1}$ \\
\hline VIIa & VIIIa $^{\mathrm{a}}$ & 97 & 0.87 \\
VIIb & VIII'b $^{\mathrm{a}}$ & 96 & 0.55 \\
VIIc & VIIIIc $^{\mathrm{a}}$ & 92 & 0.75 \\
VIId & VIIId $^{\mathrm{a}}$ & 94 & 0.74 \\
VIIe & VIIII $^{\mathrm{a}}$ & 88 & 0.38 \\
VIIf & VIIIf $^{\mathrm{a}}$ & 94 & 0.48 \\
VIIg & VIIIg $^{\mathrm{a}}$ & 93 & 0.58 \\
VIIh & VIIIh $^{\mathrm{a}}$ & 94 & 0.69 \\
VIII & VIIII $^{\mathrm{b}}$ & 98 & 0.92 \\
\hline
\end{tabular}

aPolymerization was carried out with $2.0 \mathrm{mmol}$ each monomer in $8.0 \mathrm{~mL} \mathrm{NMP} \mathrm{at} \mathrm{room} \mathrm{temperature} \mathrm{for} 6 \mathrm{~h}$ under nitrogen. ${ }^{b}$ Polymerization was carried out with $2.0 \mathrm{mmol}$ each monomer in $12.0 \mathrm{~mL} \mathrm{NMP}$ at $30^{\circ} \mathrm{C}$ for $48 \mathrm{~h}$ under nitrogen. ${ }^{\mathrm{c}}$ Measured at $0.5 \mathrm{gdl}^{-1}$ in NMP at $30^{\circ} \mathrm{C}$. 


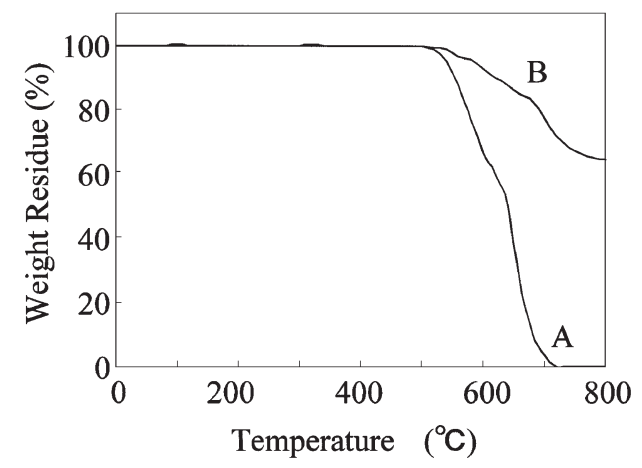

Figure 2. TG curves of polyimide IXa. at heating rate of $10^{\circ} \mathrm{C} \mathrm{min}^{-1}$ in (A) air or (B) nitrogen.

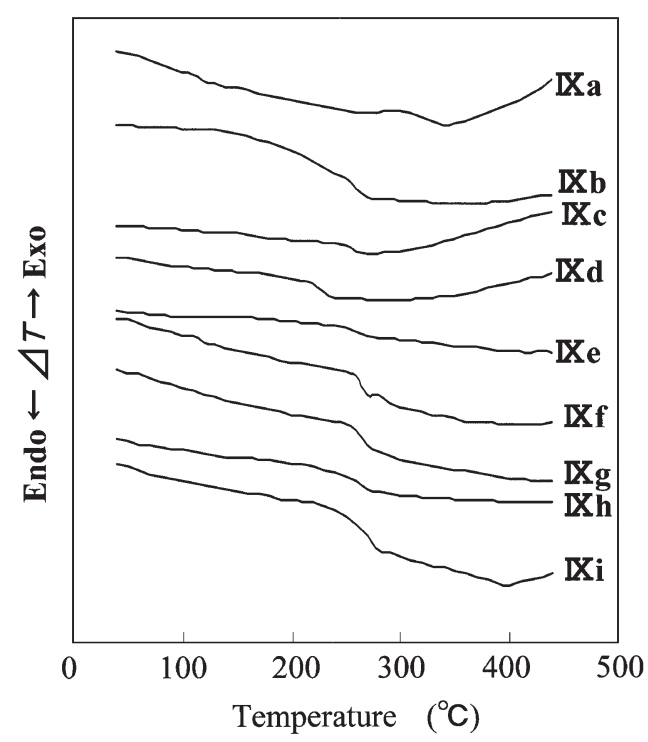

Figure 3. DSC curves for polyimides at heating rate of 10 ${ }^{\circ} \mathrm{C} \min ^{-1}$ in nitrogen.

\section{Polymer Properties}

Crystallinity of polyimides was estimated by X-ray diffraction. All polymers, even IXg, IXh and IXi which have rigid structure, were amorphous.

Thermal behavior of polyimides was evaluated by TG and DSC. Figures 2 and 3 show TG curves of polyimide IXa and DSC curves of all the polyimides, respectively, and glass transition temperature $\left(T_{\mathrm{g}}\right)$ and $10 \%$ weight loss temperature $\left(T_{10}\right)$ are summarized in Table II. $T_{\mathrm{g}}$ of the corresponding ODA-based polyimides without phenyl groups at 2,2'-position of the phenyl ether are also shown in Table II for comparison. None of the present polyimides expect IXe lost weight below $470{ }^{\circ} \mathrm{C}$ in air or nitrogen, and $T_{10}$ in air and nitrogen were in the range of $544-580^{\circ} \mathrm{C}$ and $595-639^{\circ} \mathrm{C}$, respectively, and had similar thermal stabilities to polyimides without phenyl groups at $2,2^{\prime}-$ position of the phenyl ether. The thermal stability of polyimide IXe was reduced.

The present polyimides had $T_{\mathrm{g}}$ in the range of 220$310^{\circ} \mathrm{C} . T_{\mathrm{g}}$ values of polyimides IXb, IXf, IXh and
Table II. Thermal behavior of aromatic polyimides

\begin{tabular}{cccc}
\hline Polyimides & $T_{\mathrm{g}}{ }^{\mathrm{a}} /{ }^{\circ} \mathrm{C}$ & $T_{10}{ }^{\mathrm{b}} /{ }^{\circ} \mathrm{C}$ & $T_{10}{ }^{\mathrm{c}} /{ }^{\circ} \mathrm{C}$ \\
\hline IXa & $309(400)^{\mathrm{d}}$ & 563 & 622 \\
$\mathbf{I X b}$ & $253(234)^{\mathrm{d}}$ & 550 & 615 \\
$\mathbf{I X c}$ & $257(269)^{\mathrm{d}}$ & 560 & 620 \\
$\mathbf{I X d}$ & $226(224)^{\mathrm{d}}$ & 558 & 615 \\
$\mathbf{I X e}$ & $262(294)^{\mathrm{d}}$ & 544 & 595 \\
$\mathbf{I X f}$ & $260(232)^{\mathrm{d}}$ & 560 & 627 \\
$\mathbf{I X g}$ & $260(236)^{\mathrm{d}}$ & 560 & 625 \\
$\mathbf{I X h}$ & $263(243)^{\mathrm{d}}$ & 568 & 635 \\
$\mathbf{I X i}$ & $270(244)^{\mathrm{d}}$ & 580 & 639 \\
\hline
\end{tabular}

${ }^{a}$ Determined by DSC in nitrogen at a heating rate of 10 ${ }^{\circ} \mathrm{C} \mathrm{min}^{-1}$. ${ }^{\mathrm{b}}$ Temperature at which $10 \%$ weight loss was recorded by TG at a heating rate of $10{ }^{\circ} \mathrm{C} \mathrm{min}^{-1}$ in air. ${ }^{\mathrm{c}}$ Temperature at which $10 \%$ weight loss was recorded by $\mathrm{TG}$ at a heating rate of $10{ }^{\circ} \mathrm{Cmin}^{-1}$ in $\mathrm{N}_{2} .{ }^{\mathrm{d}} T_{\mathrm{g}}$ values of the corresponding ODAbased polyimides.

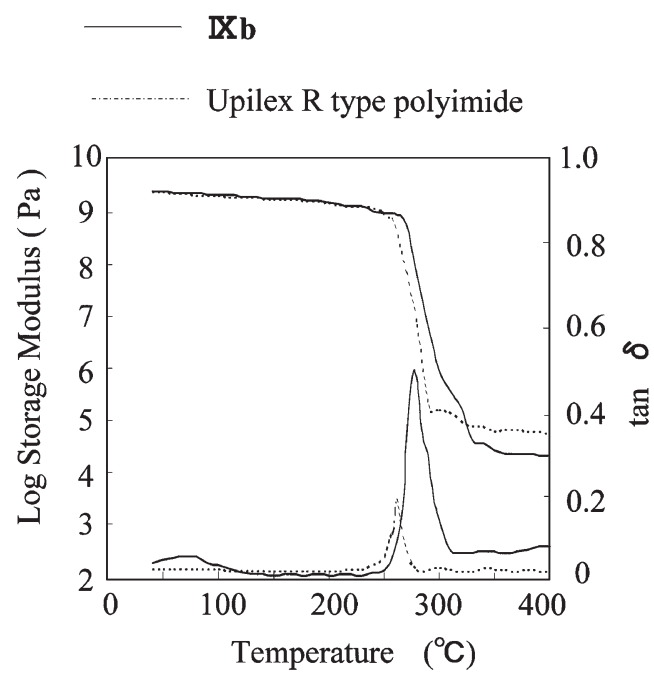

Figure 4. Dynamic mechanical behavior of polyimide IXb and polyimide prepared from 4,4'-diaminodiphenyl ether and VIIb.

IXi having linear phenylene structure were slightly higher than those of the corresponding ODA-based polyimides. However, $T_{\mathrm{g}}$ value of the polyimide IXa which was prepared from pyromellitic dianhydride was much lower than the corresponding polyimide based on ODA. This reason is not clear. The high $T_{\mathrm{g}}$ value of the polyimide from ODA and pyromellitic dianhydride was thought to be due to the chain packing originated from high electron affinity of pyromellitic dianhydride. ${ }^{21,22}$ The phenyl groups of IXa may disturb the chain packing. $T_{\mathrm{g}}$ values of polyimides IXc and IXe having connecting groups were slightly lower than those of corresponding ODA-based polyimides. It was suggested that the phenyl groups at $2,2^{\prime}$-position of the phenyl ether had a influence on both the chain mobility and chain packing of the polyimides. 


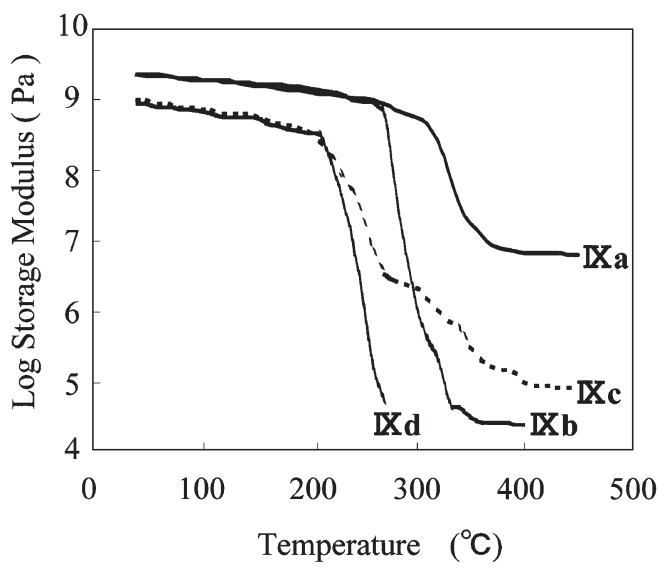

Figure 5. Storage modulus of polyimides IXa, IXb, IXc and IXd.

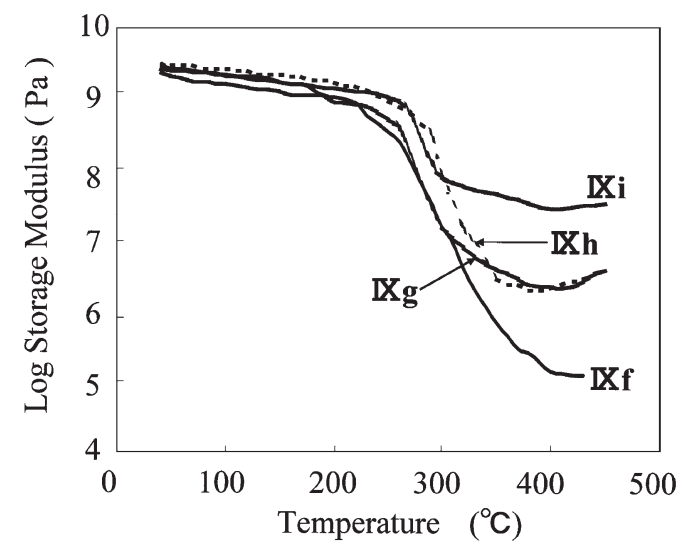

Figure 6. Storage modulus of polyimides IXf, IXg, IXh and IXi.

Table III. Solubility of aromatic polyimides

\begin{tabular}{cccccccc}
\hline Polyimide & NMP & DMAc & DMF & $m$-cresol & Pyridine & THF & Methanol \\
\hline IXa & ++ & ++ & ++ & ++ & ++ & -- & -- \\
IXb & ++ & ++ & ++ & ++ & ++ & -- & -- \\
IXc & ++ & ++ & ++ & ++ & ++ & -- & -- \\
IXd & ++ & ++ & ++ & ++ & ++ & - & -- \\
IXe & ++ & ++ & ++ & ++ & ++ & - & -- \\
IXf & ++ & - & - & ++ & ++ & -- & -- \\
IXg & ++ & + & + & + & -- & -- & -- \\
IXh & ++ & + & + & + & -- & -- & -- \\
IXi & - & - & - & - & -- & -- & -- \\
\hline
\end{tabular}

Solubility: ++ , soluble on heating; + , precipitation after cooling hot solution; - , partially soluble on heating; --, insoluble.

Figure 4 shows temperature dependence of the dynamic storage modulus $\left(\mathrm{E}^{\prime}\right)$ and $\tan \delta$ for polyimide $\mathbf{I X b}$ and polyimide (Upilex $\mathrm{R}$ type polyimide) prepared from 4,4'-diaminodiphenyl ether and VIIb. As shown in $T_{\mathrm{g}}$ values determined by DSC (Table II), regarding the peak temperature in the $\tan \delta$ curves, polyimide IXb showed a $T_{\mathrm{g}}$ at $278^{\circ} \mathrm{C}$, and the corresponding ODA-based polyimide from showed slightly lower $T_{\mathrm{g}}$ at $263^{\circ} \mathrm{C}$. For polyimide $\mathbf{I X b}, \mathrm{E}^{\prime}$ decrement at the $T_{\mathrm{g}}$ was larger than that for the Upilex $\mathrm{R}$ type polyimide. The effect of the phenyl groups at $2,2^{\prime}-$ position was also observed in the dynamic mechanical property of the polyimide.

Figure 5 shows temperature dependence of the dynamic storage modulus for the present polyimides IXa, IXb, IXc and IXd, and Figure 6 shows those of polyimides IXf, IXg, IXh and IXi. We could not determine the storage modulus of polyimide IXe because IXe was not obtained as film. The modulus decreased rapidly around $200-250^{\circ} \mathrm{C}$ to a very low level (below $10^{5} \mathrm{~Pa}$ ) for $\mathbf{I X b}$, IXc, and IXd without showing a plateau region. As observed in the case of previously prepared polyimides, ${ }^{16-19}$ polyimide IXf, IXg, IXh and IXi having rigid linear phenylene structure showed a plateau region above $300^{\circ} \mathrm{C}$, the decrement in the modulus at the glass transition decreased with the number of phenylene units.

Table III lists qualitative solubility of the present polyimides. All the polyimides were insoluble in organic solvents at room temperature. However, almost all the polyimides, even IXf, IXg and IXh, which had rigid structures, were soluble in NMP, DMAc, DMF, and $m$-cresol on heating. Interestingly, the polyimides except IXg and IXh never precipitated in spite of insolubility at room temperature when the hot solution was cooled to room temperature. The presence of the phenyl groups at 2,2'-position of the phenyl ether improved the solubility of polyimides drastically. Such the improvement of the solubility by the introduction of bulky substituents were previously reported in many kinds of aromatic polyimides. ${ }^{23-31}$

In conclusion, we successfully improved the solubility of ODA based polyimides by introducing phenyl groups at 2,2'-position of the phenyl ether without decreasing the thermal and thermo-mechanical properties.

Acknowledgment. The authors thank Prof. Katsumichi Ono in Ibaraki University for important discussion and improving manuscript. 


\section{REFERENCES}

1. P. E. Cassidy, "Thermally Stable Polymer," Marcel Dekker, New York, 1980, chapt. 4.

2. K. L. Mittal, "Polyimides: Synthesis, Characterization, and Applications," Plenum Press, New York, 1984.

3. M. I. Bessonov, M. M. Koton, V. V. Kudryavtsev, and L. A. Lauias, "Polyimides: Thermally Stable Polymer," Consultants Bureau, A Division of Plenum Publishing Co., New York, 1987.

4. C. Feger, M. M. Khojasteh, and J. M. MacGrath, "Polyimides: Materials, Chemistry and Characterization," Elsevier, Amsterdam, 1989.

5. M. I. Bessonov and V. A. Zubkov, "Polyamic acid and Polyimides: Synthesis and Transformation and Structure." CRC Press, Boca Raton, FL, 1993.

6. C. Feger, M. M. Khojasteh, and S. E. Molis, "Polyimides: Trends in Materials and Applications," Society of Plastic Engineers, Mid Hudson Section, New York, 1996.

7. M. K. Ghosh and K. L. Mittal, Polyimides: "Fundamentals and Applications," Marcel Dekker, New York, N.Y., 1996.

8. P. M. Hergenrother, Polym. J., 19, 73 (1987).

9. I. Mita, Kinouzairyou, 1, 1 (1981).

10. M. Hasegawa, N. Sensui, Y. Shindo, and R. Yokota, Macromolecules, 32, 387 (1999).

11. St. A. K. Clair and St. T. L. Clair, Polym. Mater. Sci. Eng., 51, 62 (1984).

12. St. A. K. Clair, St. T. L. Clair, W. S. Slemp, and K. S. Ezzel, Proc. 2nd Int. Conf. on Polyimides, Elleville, NY, 333 (1985).

13. St. A. K. Clair and W. S. Slemp, SAMPE J., 21, 28 (1985).
14. St. A. K. Clair and St. T. L. Clair, Polym. Mater. Sci. Eng., 55, 396 (1986).

15. St. A. K. Clair, St. T. L. Clair, and W. P. Winfree, Polym. Mater. Sci. Eng., 55, 396 (1986).

16. A. Morikawa, Polym. J., 32, 275 (2000).

17. A. Morikawa and Y. Hosoya, Polym. J., 34, 544 (2002).

18. A. Morikawa and K. Ono, Polym. J., 32, 948 (2000).

19. A. Morikawa and K. Ono, High Perform. Polym., 13, S73 (2001).

20. T. Oh-e, N. Miyaura, and A. Suzuki, Synlett, 221 (1990).

21. M. Hasegawa, M. Kochi, I. Mita, and R. Yokota, Eur. Polym. J., 25, 349 (1989).

22. M. Hasegawa and K. Horie, Prog. Polym. Sci., 26, 259 (2001).

23. Y. Imai, N. N. Maldar, and M. Kakimoto, J. Polym. Sci., Polym. Chem. Ed., 22, 2189 (1984).

24. H.-J. Jeong, A. Kobayashi, M. Kakimoto, and Y. Imai, Polym. J., 26, 373 (1994).

25. H.-J. Jeong, M. Kakimoto, and Y. Imai, J. Polym. Sci., Polym. Chem. Ed., 29, 39 (1991).

26. H.-J. Jeong, M. Kakimoto, and Y. Imai, J. Polym. Sci., Polym. Chem. Ed., 29, 1691 (1991).

27. Y. Ohishi, M. Ishida, M. Kakimoto, Y. Imai, and T. Kurosaki, J. Polym. Sci., Polym. Chem. Ed., 30, 1027 (1992).

28. I. K. Spiliopoulos and J. A. Microyannidis, Macromolecules, 31, 1236 (1998).

29. I. K. Spiliopoulos and J. A. Microyannidis, Macromolecules, 31, 515 (1998).

30. A. Morikawa and T. Hatakeyama, Polym. J., 31, 66 (1999).

31. Y. Imai, High Perform. Polym., 7, 337 (1995). 